\title{
MUSCLE REGENERATION IN EXPERIMENTAL ANIMALS AND IN MAN*
}

\section{The Cycle of Tissue Change that Follows Trauma in the Injured Limb Syndrome}

\author{
David Allbrook, Perth, Western Australia \\ University of Western Australia \\ W. DE C. Baker, Sydney, Australia \\ Prince of Wales Hospital, Sydney \\ W. H. Kirkaldy-Willis, Saskatoon, Canada \\ Department of Surgery and Rehabilitation, University of Saskatchewan
}

The ability of adult skeletal muscle fibres to regenerate after injury is now generally accepted by cytologists but perhaps still rather poorly understood by many who are engaged in the treatment of patients who have sustained an injury.

The object of this paper is to draw attention to certain relevant facts that have been established in this field during the past decade. An attempt is made to relate this knowledge to the clinical management of trauma in human patients.

The paper is in four parts: 1) A review of relevant laboratory work in this field. 2) A histological description of an experimental series of soft-tissue injuries, associated with fractures in vervet monkeys. 3) A histological report of muscle biopsies in a series of patients who had sustained fractures of the limb bones from direct injury. 4) A discussion of these findings in relation to the principles that clinical experience indicates are of importance in the treatment of the " injured limb syndrome." This term is used to emphasise the thesis that the fracture is merely a part, though an important part, of the total pathological process which inevitably involves soft tissue.

\section{REVIEW OF RECENT WORK IN THE FIELD OF MUSCLE DEGENERATION AND REGENERATION}

After injury to a limb or after ischaemia it is common to find a picture of patchy damage in which damaged fibres or groups of fibres are scattered among apparently intact fibres. The following account is based on work done with the electron microscope by Moore, Ruska and Copenhaver (1956) and by Allbrook (1962). This technique has enabled more precise analysis of the changes occurring inside a damaged fibre.

The simplest and least severe injury to muscle fibres or cells, caused by physical pressure or temporary ischaemia, is followed by rapid physical and electrical recovery (Harman and Gwinn 1949, Allbrook 1952). Fibres affected show intracellular oedema, loss of definition of myofilaments (the actin-myosin chains constituting the contractile myofilaments of muscle), and a widely dispersed granularity. The sarcotubular system (the endoplasmic reticulum which is responsible for the conduction of membrane polarisation within the cell) appears distended by oedema. The mitochondria are enlarged and have well defined cristae. Moore et al. (1956) found that there was no loss of succinic dehydrogenase in this or in more severe mitochondrial lesions. In such fibres it seems probable that functional and morphological recovery is both rapid and complete, because material examined after twenty-four hours shows either fibres that appear normal or fibres undergoing phagocytosis (Allbrook 1962).

The accumulated evidence indicates that more severely damaged necrotic fibres do not recover, either functionally or morphologically, but go through a cycle of phagocytosis and regeneration. Such severely damaged fibres when seen a few hours after injury are oedematous. There is a loss of the transverse banding of the sarcomeres. The $Z$ discs disappear. Many myofibrils are distorted or broken and their constituent filaments disappear. The sarcoplasm has a coarse or finely granular appearance. In some fibres there is an increase in the number

* The work on which this paper is based was carried out at the University of East Africa Medical School, Kampala, Uganda, and at King George VI Hospital and the Medical Research Laboratory, Nairobi, Kenya. 
of lipoid droplets within the fibre. The mitochondria are swollen and may be many times the normal size. Their internal structures may be partly or completely absent. They too may contain lipoid droplets which on occasion completely fill the organelle.

There is distension of the sarcotubular system together with rupture and disintegration of the tubules. Both discoid and hyaline degeneration can often be seen in the same preparation. There is some evidence that the variety of the degenerative change may depend on the state of contraction of the damaged fibre at the time of fixation. The constant feature is disappearance of $Z$ discs, to which filaments are attached, so that if the myofilaments contract the appearance will be that of discoid degeneration, whereas if the fibre is relaxed no discoid banding results and the appearance will be that of hyaline or granular degeneration. The sarcolemmal tube that surrounds the muscle fibre is usually intact though thickened. It may be stripped off the sarcoplasm, distorted or collapsed. The tissue space between fibres is distended with oedema fluid. Within twelve hours there is an invasion of the tissue space of the damaged area, including the muscle fibres, by polymorphonuclear neutrophils from the vascular system. By four days after injury these cells have decreased in number. There are now many phagocytic cells in the tissue spaces and within damaged muscle fibres. Autoradiographic studies suggest that these migrate from outside the area of the damaged tissue (Bintliff and Walker 1960).

Between four and six days after injury the sarcolemmal tubes, now cleared of their content of cellular debris, are lined with columns of myoblasts. The cytoplasm of these myoblasts is basophilic and they have the large nuclei with prominent nucleoli that are associated with embryonic or regenerating cells. By a process of exclusion Walker (1963) narrowed their site of origin to muscle cells. Muir, Kanji and Allbrook (1965) described and implicated the satellite cells of Mauro (1961) as the source of these cells. These myoblasts typically form an elongated syncytium along the sarcolemmal tubes where chains of nuclei are seen. Examination at this stage by electron microscopy reveals myofilaments beneath the plasma membrane of this syncytium (Allbrook 1962). The work of Holtzer, Marshall and Finck (1957) with fluorescent antimyosin indicates that myofilaments are rapidly laid down on either side of the chains of nuclei. Within a few days myotubes appear which contain peripheral bundles of myofibrils arranged around a central core of nuclei and sarcoplasm. Many such forms are still present at ten and fourteen days after injury. However, by the end of three weeks muscle fibres that are nearly normal in size and appearance dominate the picture in the injured area. That they are not surviving intact fibres is shown by the fact that they may split longitudinally and form cross connections with each other, as seen in cardiac muscle. By electron microscopy it can be seen that within a single old surviving sarcolemmal tube several new fibres may be present, each invested with its own new sarcolemmal tube. Such fibres must be regenerates.

An important fact which has escaped recognition until recently is that muscle fibres are formed by a coalescence of individual myoblasts. The evidence for this is now very strong, derived as it is from tissue culture observations on regenerating adult cardiac and embryonic and neonatal skeletal muscle (Pogogeff and Murray 1946, Capers 1960, and Konigsberg 1961). The strong supporting evidence for this view is based on studies that employ the labelling of muscle nuclei with radioactive isotopes and of individual muscle cells with fluorescent antimyosin to detect the nature of sample cell populations (Holtzer, Marshall and Finck 1957; Walker 1963). In the tissue spaces there is attempted formation of new muscle fibres simultaneously with regeneration within the surviving sarcolemmal tubes. The mechanism of regeneration is identical. Unless the new fibres obtain a nerve supply they will not grow, but remain at the myotube stage and then slowly atrophy (Saunders and Sissons 1953). Such fibres may often be seen as chains of nuclei with minimal surrounding sarcoplasm several weeks or months after injury. Along with muscle regeneration fibroblasts increase in number in the tissue spaces. The network of collagen fibres deposited by them sometimes impedes the longitudinal growth of the regenerating muscle fibres and results in the formation of " muscle giant cells" (Clark 1946). The collagenous reticulum of scar tissue also impedes the 
growth of regenerating nerve axons, resulting in the aneural and therefore functionally useless muscle just described (Allbrook and Aitken 1951). Within a single specimen, taken some two months after injury, most of the late appearances (normal fibres, cross connected fibres, aneural degenerate fibres, muscle giant cells and collagenous scar tissue) can usually be seen.

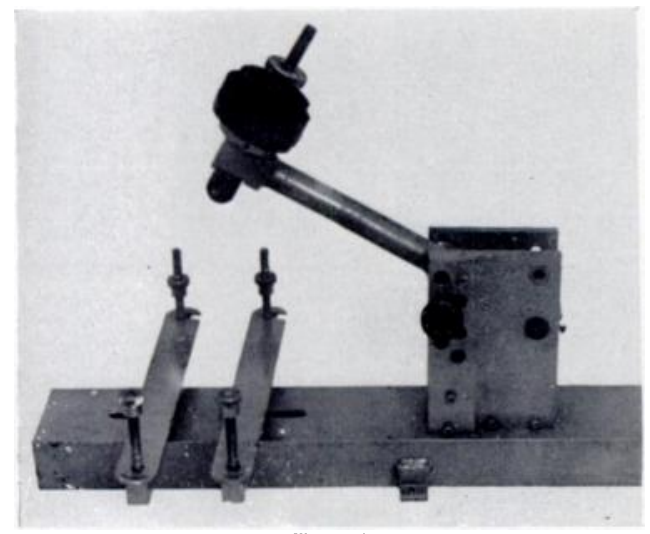

Fig. 1

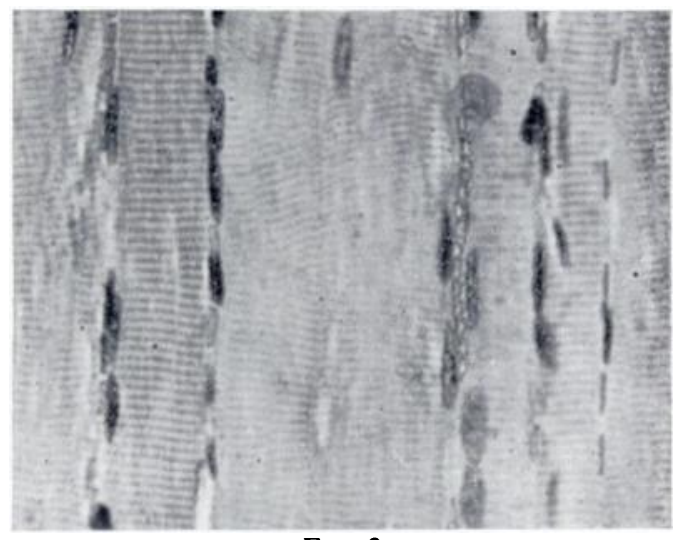

Fig. 2

Figure 1-Apparatus designed by Professor C. A. Judson and Mr S. R. Lamond of University College, Nairobi, to produce injury to muscle and fracture of the fibula in vervet monkeys. Figure 2-Normal tibialis anterior muscle of the vervet monkey. Note the width of the fibres, the cross striations and the dark, elongated peripherally sited nuclei. $(\times 400$.)

\section{EXPERIMENTAL FRACTURES WITH SOFT-TISSUE INJURY}

Material and methods-Twelve vervet monkeys were anaesthetised with intravenous pentobarbitone sodium. A force of 96 pound/inches was applied to the antero-lateral aspect of the leg over the fibula, midway between knee and ankle, by means of a striker which could be dropped from different heights (Fig. 1). The force damaged the soft tissues and fractured the fibula. The centre of the injured area was marked by a small subcutaneous blob of Indian ink. Within twenty-four hours of recovery from anaesthesia the animals were running and jumping in their cages quite normally. Biopsy was performed at six, twelve and twenty-four hours and three, six, eleven, thirty-two, forty-five and ninety days after injury. A part of the fractured fibula was removed together with its attached muscles and was placed on a card until the muscle became attached. It was then immersed in 300 millilitres of buffered formol saline. The bone was decalcified in a mixture of oxalic and citric acid. The specimen was embedded in celloidin paraffin and sections were cut in the usual way. Sections were stained with haematoxylin and eosin, phosphotungstic acid, Masson's trichrome and Movat's pentachrome stains, and specifically with periodic acid-Schiff and Feulgen reagents (Fig. 2).

\section{OBSERVATIONS}

Six hours after injury (two animals—96 pound/inches)-There was macroscopic bleeding and oedema. Within the marked "trauma area" there was disruption of groups of muscle fibres. Such fibres were often fragmented and broken cleanly and transversely across their ends, at the $\mathrm{Z}$ discs. Some were fractured in a characteristic transverse stepwise fashion. The sarcolemmal tube could sometimes be identified projecting like a structureless sleeve beyond the fibre contents. There was wide separation of fibres and there were many areas of microscopic haemorrhage. Polymorphonuclear leucocytes were the commonest white cells in the tissue spaces. Many of the fibres were apparently intact. The fractured bone ends and torn periosteum were identified.

Twelve hours after injury (two animals-96 pound/inches) - There was macroscopic bleeding and oedema. The appearances were similar to those seen at six hours except that polymorphs were seen in the tissue spaces, in surrounding muscle fibres and within the sarcolemmal sheaths of injured fibres. The damaged fibres showed discoid, granular and hyaline degeneration.

VOL. $48 \mathrm{~B}$, NO. 1, FEBRUARY 1966 
Three days after injury (three animals-59.6 pound/inches) 96 pound/inches: fracture of fibula only-Macroscopic bruising was still evident, although there was less obvious clinical oedema at the marked site. Isolated small groups of muscle fibres were damaged. These seemed

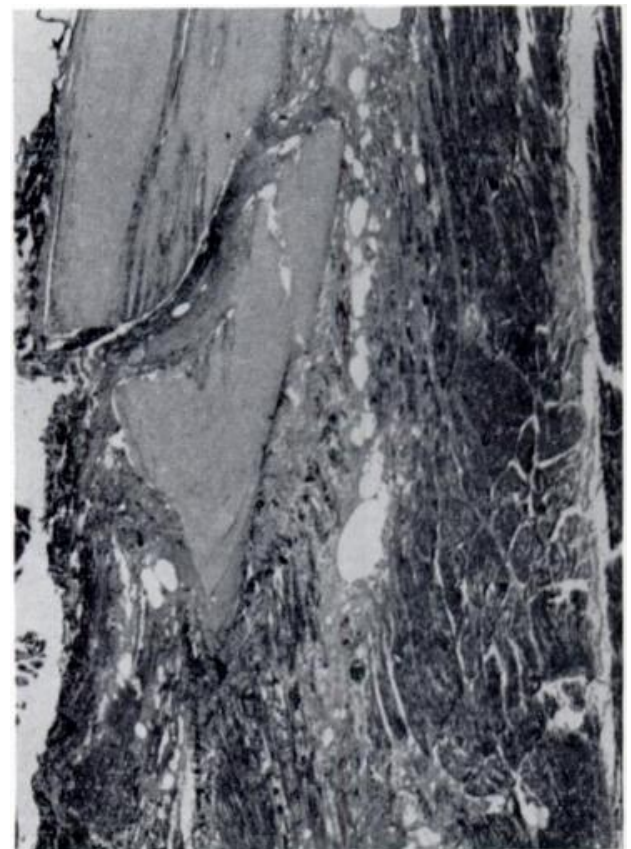

FiG. 3

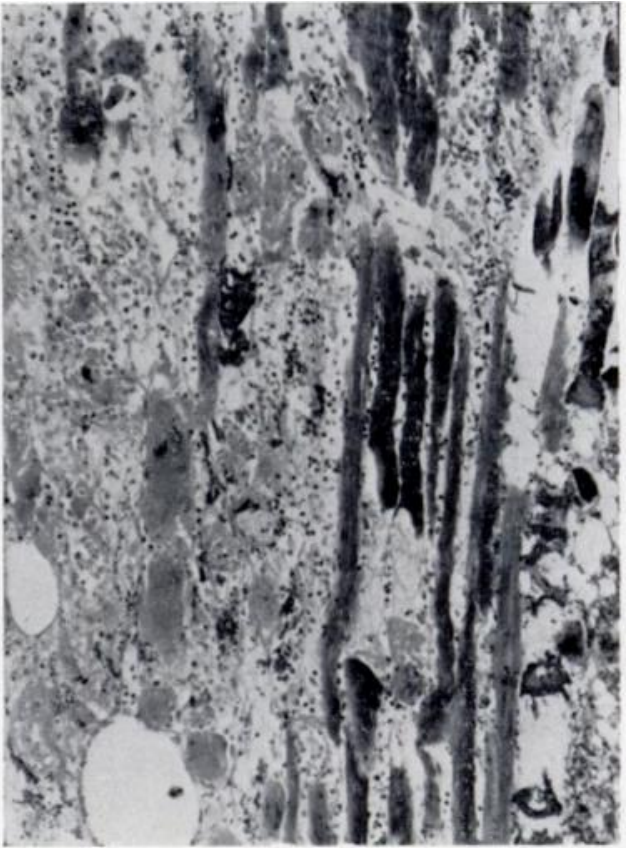

Fig. 4

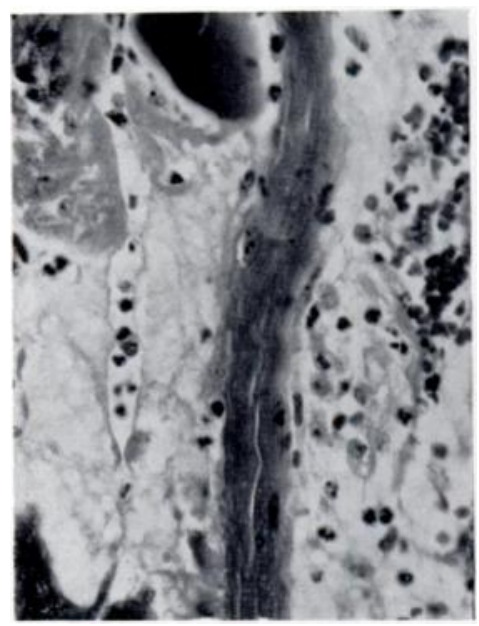

Fig. 5

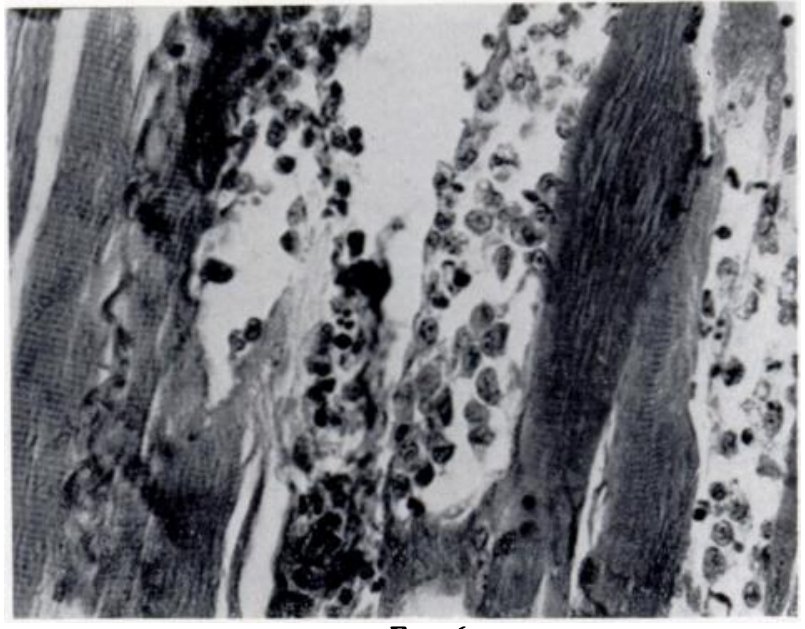

FIG. 6

Monkey. Three days after injury. Figure 3-Note the fracture of the fibula and the fragmentation of muscle. $(\times 10$.) Figure $4-A$ few short lengths or ribbons of partially intact muscle fibres are seen: throughout the greater part of the field there has been complete disintegration of muscle and there is a marked cellular infiltration. $(\times 80$.) Figure 5-One apparently intact muscle fibre is seen crossing the field: there is a marked infiltration of polymorphonuclear leucocytes and monocytic cells: several sarcolemmal sheaths can be identified: there is marked disintegration of sarcoplasm and of the contractile elements of muscle. $(\times 250$. $)$ Figure $6-$ Several more or less intact muscle fibres are seen: in the centre of the field are numerous phagocytic cells within an intact sarcolemmal sheath. $(\times 400$.)

to be random in distribution. There were still many apparently normal fibres in the trauma area. The damaged fibres exhibited the same appearance as at six and twelve hours except that phagocytosis within fibres and in the tissue spaces was now in progress. The commonest 


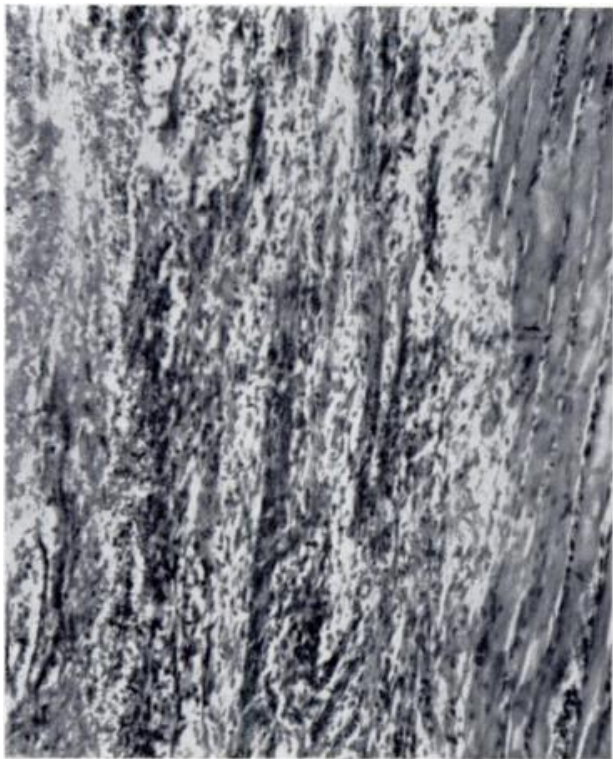

Fig. 7

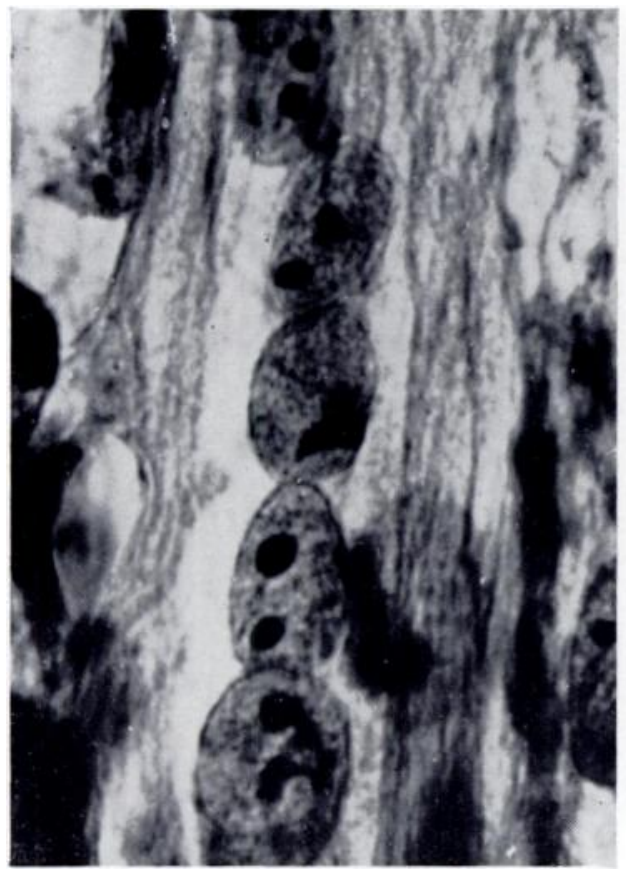

FIG. 9

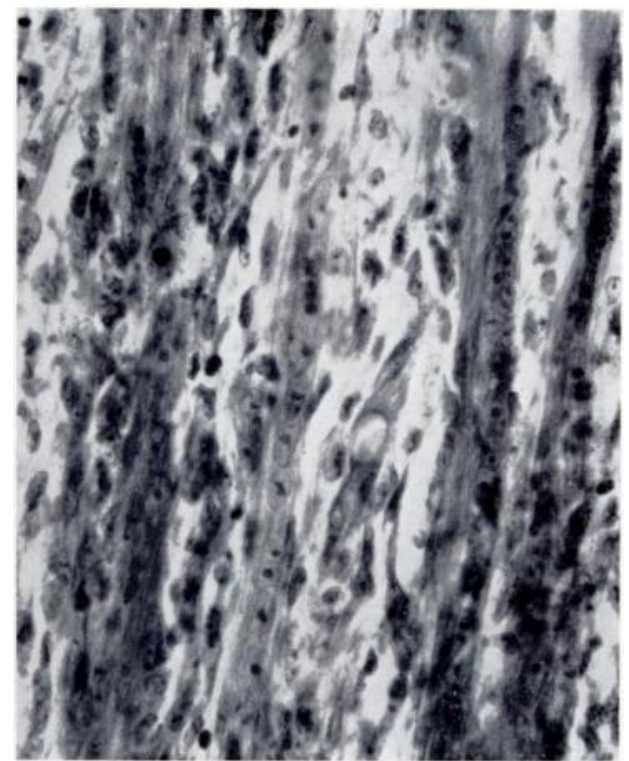

FIG. 8

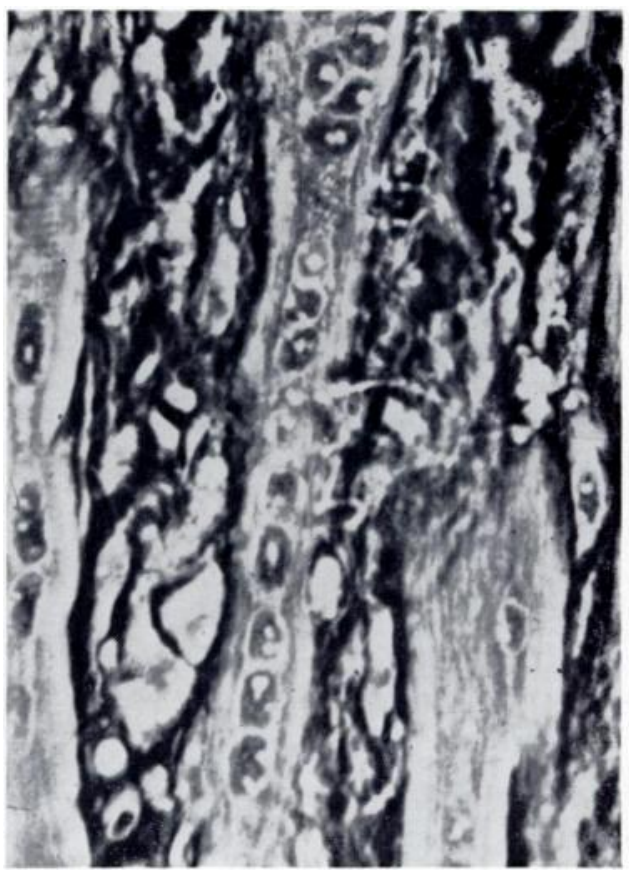

FIG. 10

Monkey. Six days after injury. Figure 7-Several normal fibres are seen at the right of the field; the remainder of the field is occupied by an intense cellular infiltration. $(\times 80$.) Figure 8-Part of the field seen in Figure 7: a number of chains of large, pale myoblast nuclei can be identified: most of these nuclei have each two prominent nucleoli. $(\times 300$.) Figure 9-Part of the field seen in Figure 8: a single chain of myoblast nuclei can be seen in the centre of the field: each nucleus has two prominent nucleoli: newly formed contractile protein filaments can be seen either side of the myoblast chain. $(\times 1,800$.) Figure 10-Phase contrast: several newly formed fibres can be seen: typical myoblast nuclei can be identified, situated centrally in the new fibre segments. $(\times 800$.) 
cell type in the still distended tissue spaces was the polymorphonuclear leucocyte but macrophages and basophilic round cells were also present (Figs. 3 to 6).

Six days after injury (one animal-96 pound/inches)-The fibula was fractured. There was

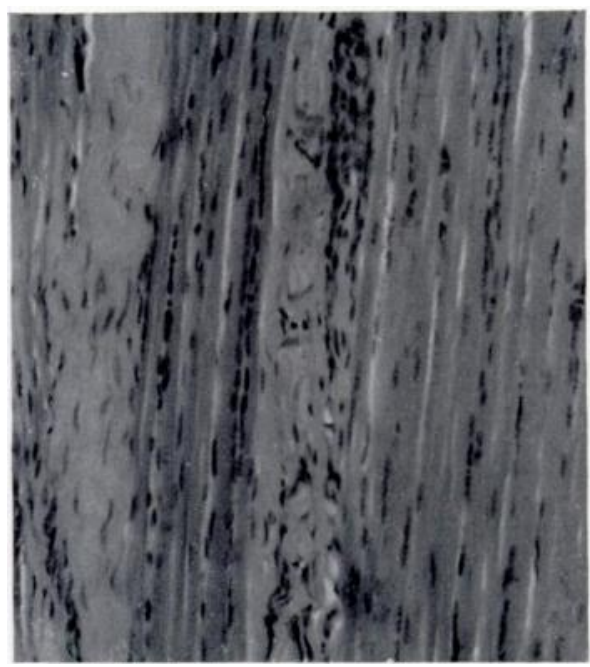

FIG. 11

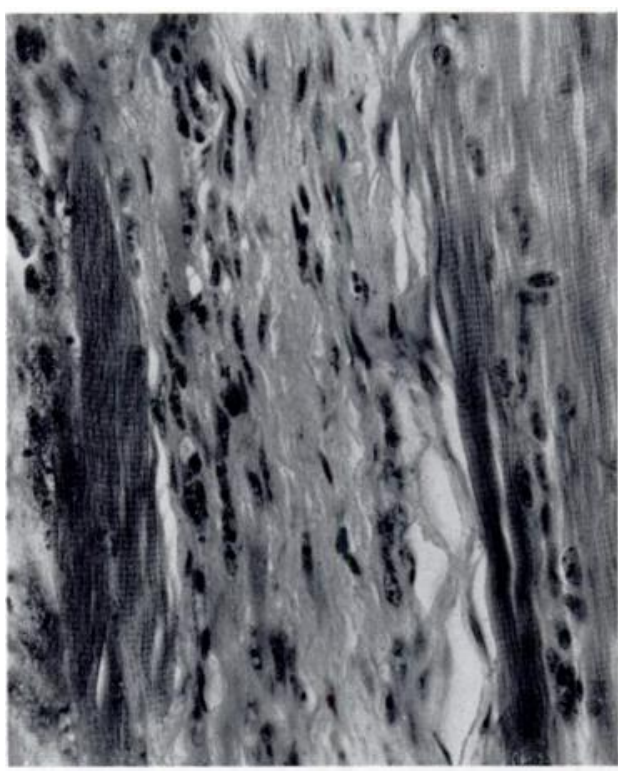

Fig. 12

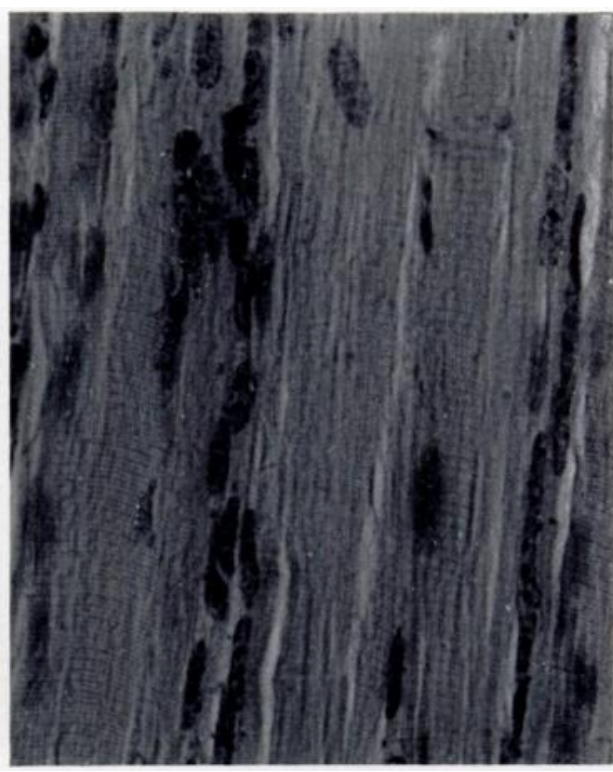

Fig. 13

Monkey. Twelve days after injury. Figure 11-Numerous newly formed thin fibres can be seen their nuclei are closely packed together in chains: some of these chains appear to be central and others to be sited peripherally: two bands of collagen can be seen, one at the left, the other in the centre of the field. $(\times 150$.) Figure 12-Part of the field seen in Figure 11: in the centre is a wide band of collagen: numerous fibroblasts can be seen: left and right newly formed fibres with cross striations and chains of active nuclei can be identified. $(\times 300$. $)$ Figure 13-Part of the same field as Figure 11: the whole field is occupied by newly formed muscle fibres: cross striations are clearly seen: the nuclei are large and active: they contain prominent nucleoli; some appear to be central and others peripheral. $(\times 600$.)

some bruising and oedema of the tissues beneath the deep fascia. Throughout most of the sections many muscle fibres appeared normal but others were fragmented and showed hyaline and discoid degeneration. There were polymorphs, histiocytes and erythrocytes in the tissue 
spaces. A striking appearance at this stage was the lines of myoblasts both within intact sarcolemmal sheaths and in the tissue spaces. In some of these myoblast syncytia myofibrils were visible. There were many fibroblasts and already newly formed collagen fibres were seen in the oedematous tissue spaces. The overall picture was of intense regenerative activity (Figs. 7 to 10).

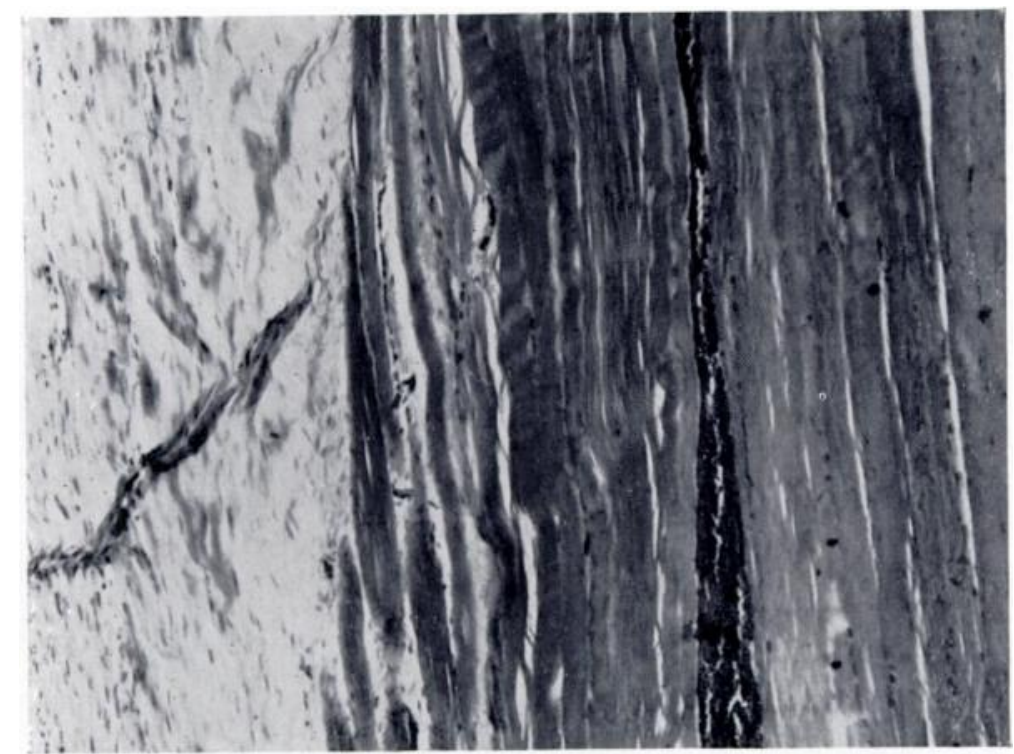

Fig. 14

Monkey. Six weeks after injury: the left third of the field is occupied by collagen fibres: the right two-thirds are occupied by newly formed muscle fibres. $(.100$.

Twelve days after injury (one animal-96 pound/inches)-The fibula was fractured. Macroscopically no oedema or bruising was seen. In the sections examined from the "marked" injured zone normal fibres predominated. There were also zones of thin fibres with centrally placed nuclei, and rather obvious longitudinal myofibrillae. Between these were bands of collagen fibres and many fibroblasts. Immature myoblast chains were seen occasionally; this presumably indicates that there was still a potential for regeneration (Figs. 11 to 13).

Six weeks after injury (one animal: 96 pound/inches)-The biopsy field from the "marked" injured area was almost completely occupied by normal muscle fibres. Some of these, however, had cross connections. There were areas of collagenous scar tissue between the fibres and a thickened periosteum (Fig. 14).

Three months after injury (two animals: 96 pound/inches)-The muscle fibres throughout the injured zone of muscle were normal in size and appearance with the exception of fibres arising from, or closely associated with, the fracture callus.

Fig. 15

Monkey. Three months after injury showing regenerated muscle fibres of normal diameter and histological appearance. $(\times 270$. $)$

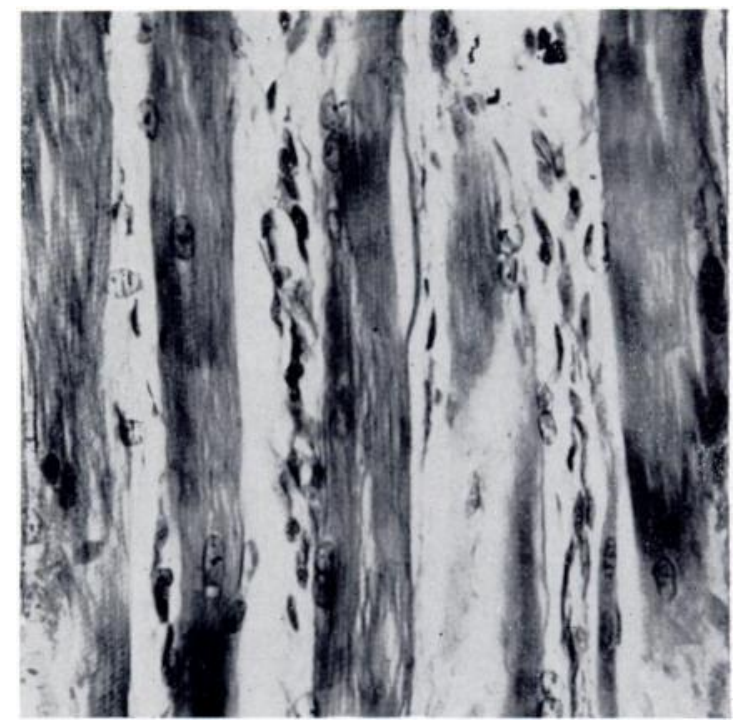

vOL. 48 B, NO. 1, FEBRUARY 1966

FiG. 15 
The bands of collagenous scar tissue seen between the muscle fasciculi were narrow, indicating possible absorption of collagen as newly formed muscle fibres increased in diameter. There was a thick but well circumscribed fibrous periosteum from which thin muscle fibres arose (Fig. 15).

\section{CONCLUSIONS}

1. After a severe localised injury of sufficient force to fracture a bone, the soft tissues as well as the bone undergo a cycle of tissue phagocytosis and cellular regeneration. In particular a proportion of the injured skeletal muscle undergoes degeneration, and this is followed by functional and morphological regeneration.

2. By six weeks muscle that had been severely injured had returned to normal, except for the presence of an excess of collagen between the new muscle fibres.

\section{MUSCLE BIOPSIES FROM HUMAN PATIENTS WITH FRACTURES OF A LIMB BONE}

Materials and methods-Eighteen of the twenty-one patients studied were treated on traction as described by Perkins (1958) for fracture of the tibia and fibula. The fractures had all been caused by direct violence. Active contractions of the muscles of the leg were commenced

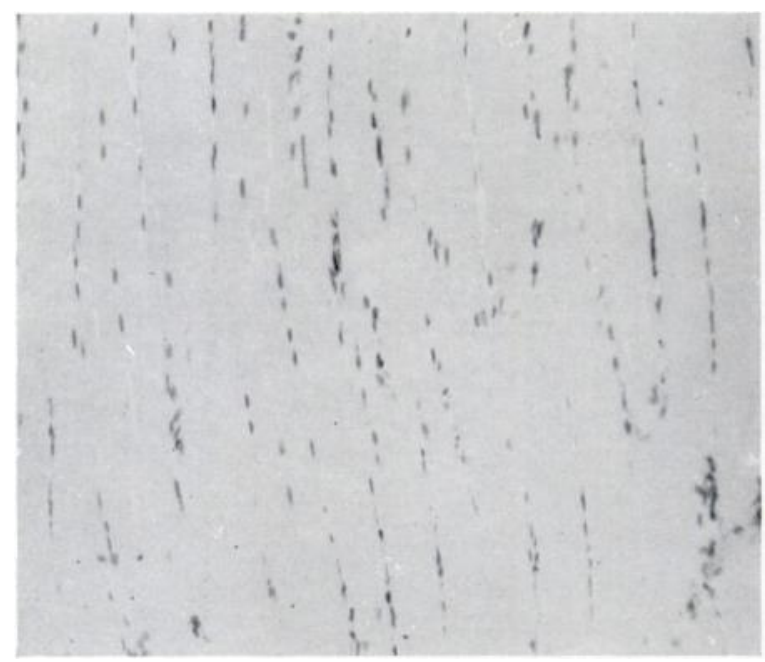

FIG. 16

Normal human tibialis anterior muscle. Note the width of the fibres and the thin elongated peripheral nuclei. $(\times 240$. $)$

within three days of admission; this was continued intensively for at least four weeks. In each patient muscle biopsies were taken during the course of an operation to treat a fracture or to suture a nerve. They were obtained at irregular intervals varying from six hours to six months from the time of injury. In each instance three pieces of muscle 1.5 centimetres long and 0.5 centimetre wide and 0.25 centimetre thick were removed. They were cut with scalpel or sharp scissors, care being taken not to bruise them. They were immediately placed on a thin card and gently stroked into position. Within three or four minutes they became firmly adherent to the card. This simple manoeuvre prevented contraction and distortion during fixation. Each specimen was then fixed separately in 300 millilitres of buffered formol saline for a week. The most interesting specimens histologically were those which, to the naked eye, appeared to be more dull and darker in appearance than normal muscle. Plum coloured material from the muscle was in fact blood clot, usually with no muscle fibres in it. Three specimens were from the brachialis muscle, two from the vastus intermedius and sixteen from the tibialis anterior. Paraffin-embedded sections were stained with haematoxylin and eosin, 
phosphotungstic acid, P.A.S. and Mallory's stain. They were examined by direct illumination and by polarised light.

\section{OBSERVATIONS}

Six hours after injury-There was fragmentation of a number of groups of muscle fibres; others were swollen but intact and lying amid apparently normal muscle fibres. The tissue

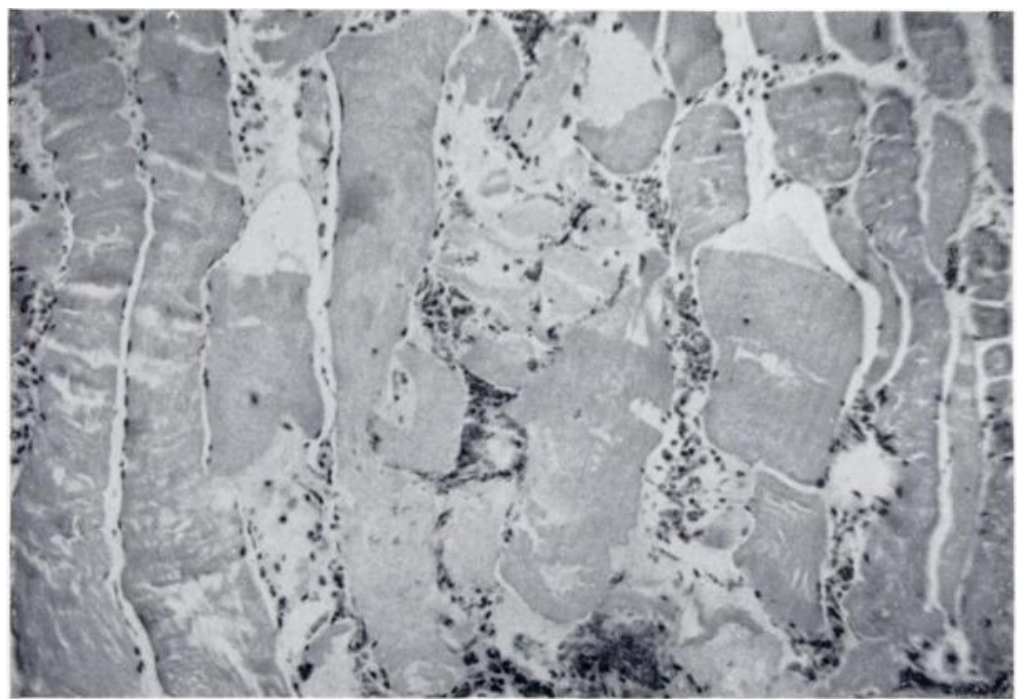

FIG. 17

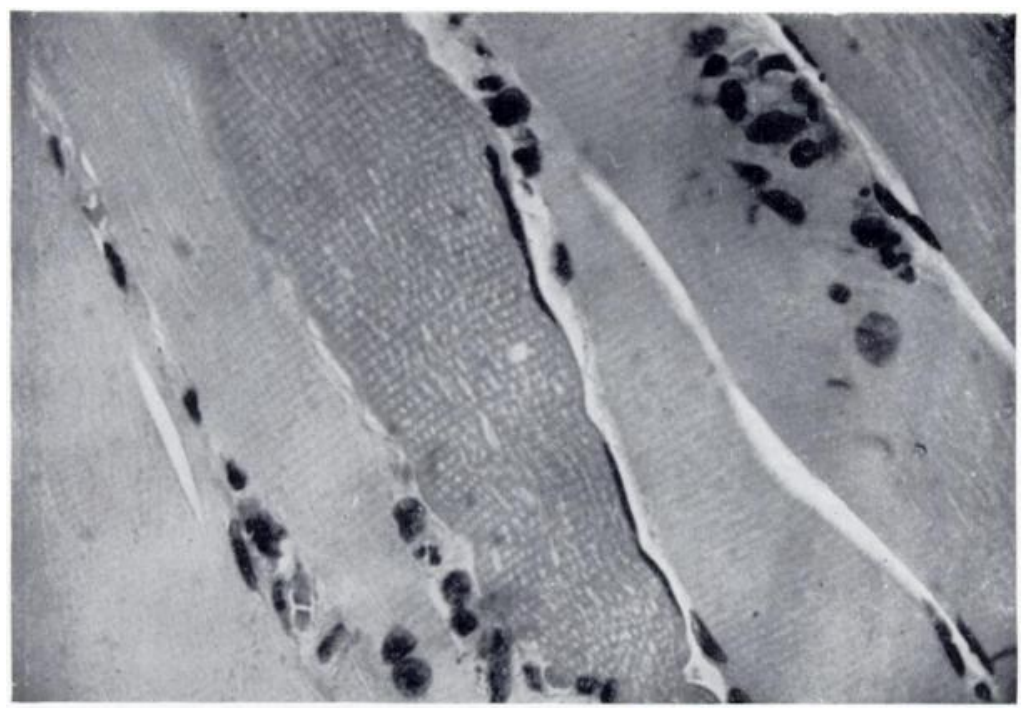

FIG. 18

Man. Six hours after injury. Figure 17-Marked fragmentation of muscle fibres: erythrocyte and polymorphonuclear infiltration in tissue spaces. $(\times 400$. Figure 18 -The central fibre shows fine vacuolar degeneration. $(\times 800$.

spaces contained numerous erythrocytes and polymorphonuclear leucocytes and some swollen fibres contained numerous small vacuoles situated near the $Z$ discs in the I bands. The longitudinal striations of such fibres were more intensely eosinophilic than those of neighbouring fibres (Figs. 17 and 18):

Three days after injury-Damaged fibres showed numerous large vacuoles near the $Z$ disc. But in these fibres no striations could be seen. However, the sarcoplasm between the vacuoles

VOL. 48 B, NO. 1, FEBRUARY 1966 
showed a filamentous structure when examined under polarised light. It is likely that this is a later stage of the vacuolar process seen at six hours (Fig. 19).

Other fibres exhibited Zenker's hyaline degeneration. In such fibres the severed end was swollen and bulbous, the sarcoplasm stained evenly but some filamentous structure could be seen under polarised light (Fig. 20). Few scattered vacuoles were seen in the sarcoplasm and the sarcolemmal tubes and the subsarcolemmal muscle nuclei appeared normal.

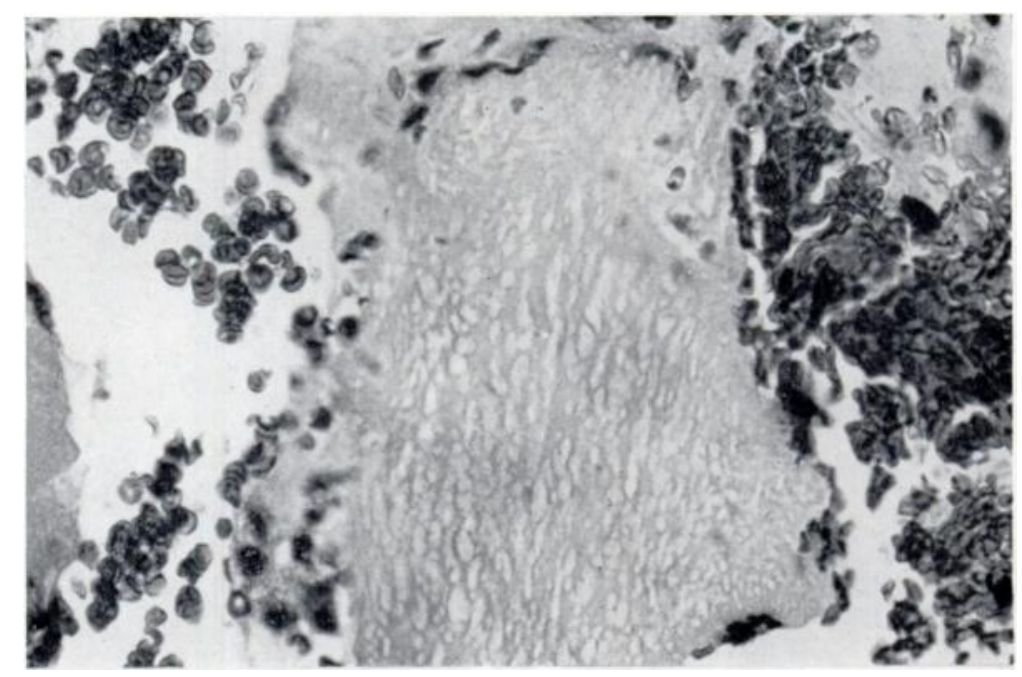

Fig. 19

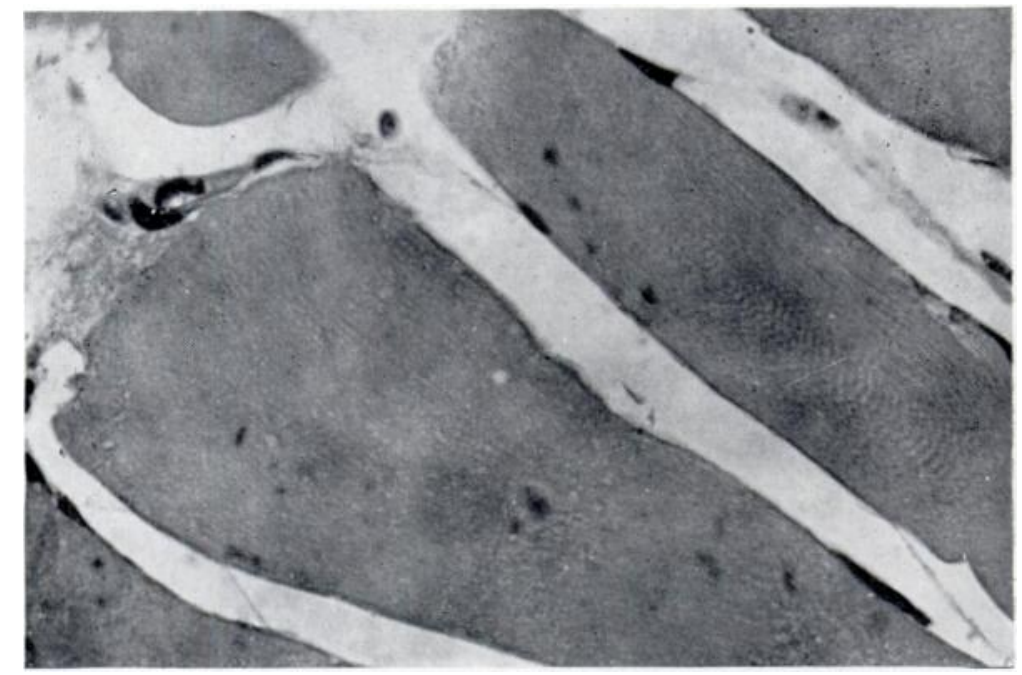

Fig. 20

Man. Three days after injury. Figure 19-Coarse vacuolar degeneration. $(\times 800$. $)$ Figure 20-The central fibre shows hyaline degeneration: the end is bulbous: the sarcoplasm is homogenous in appearance. $(\times 800$.)

Other fibres showed discoid degeneration. The A bands were prominent for the disappearance of the $\mathrm{Z}$, and $\mathrm{I}$ bands isolated the $\mathrm{A}$ bands and gave them a discoid appearance. Some of these fibres showed granular degeneration and phagocytosis farther down their length (Fig. 21).

Still other fibres exhibited a typical "granular" degeneration of the sarcoplasm which was non-luminous when viewed under polarised light. The sarcolemmal outline of these fibres 


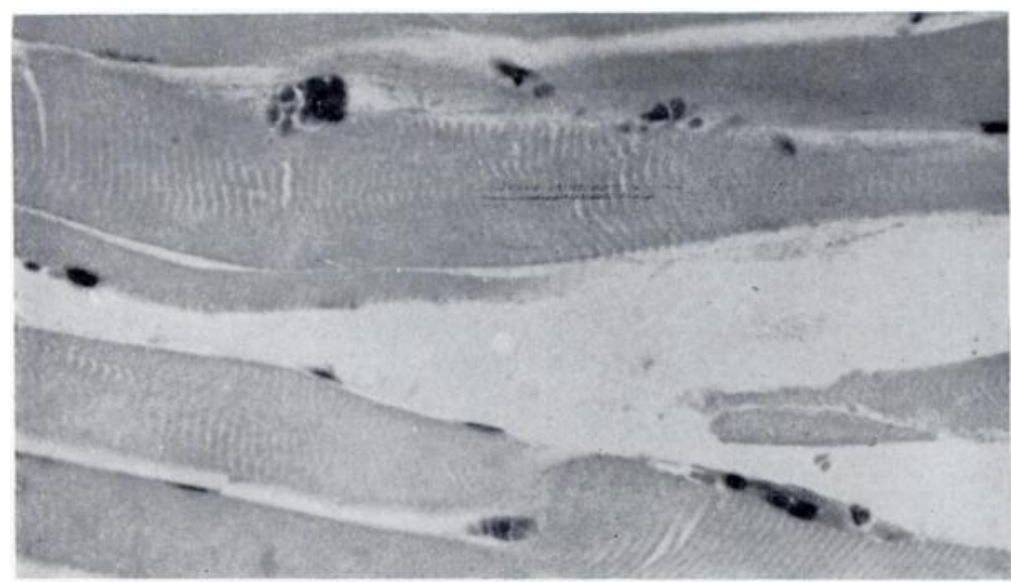

Fig. 21

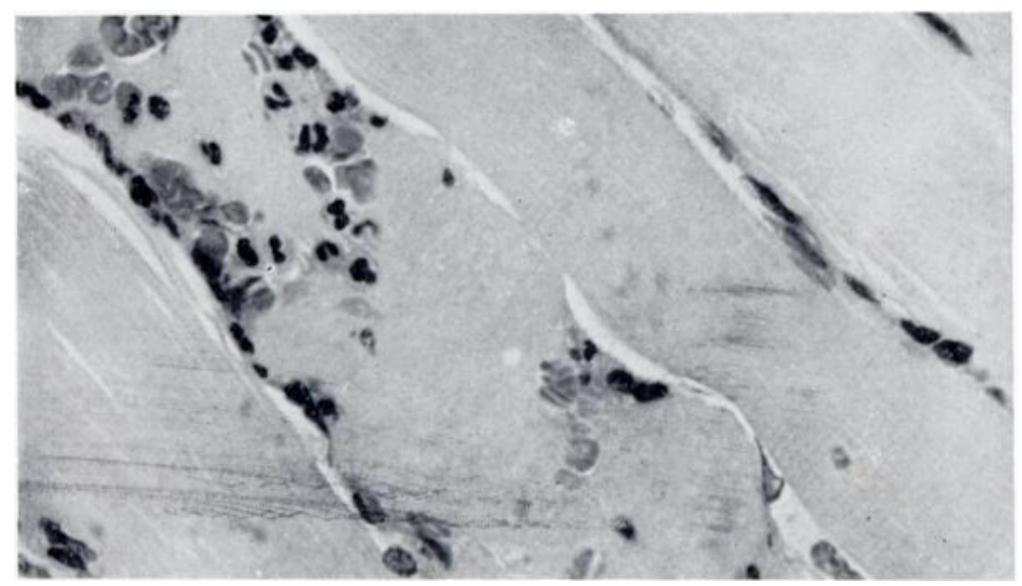

Fig. 22

Man. Three days after injury. Figure 21-The fibres show a typical discoid degeneration. $(\times 800$.) Figure 22 - The central fibre shows a granular degeneration. $(\times 800$. $)$

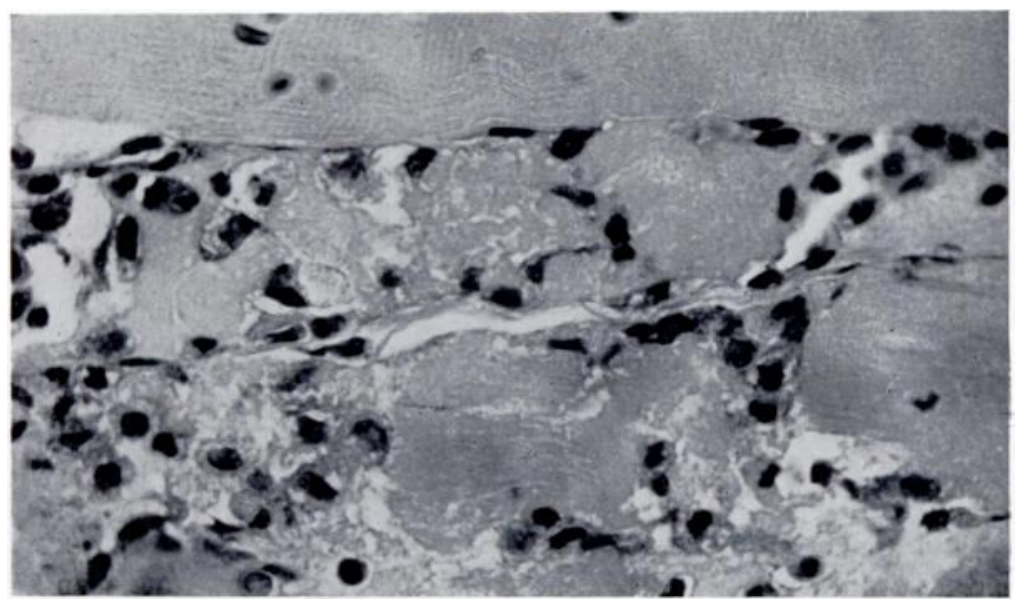

Fig. 23

Man. Four days after injury: phagocytosis of disintegrated muscle protein: numerous phagocytic cells with a large amount of cytoplasm, containing eosinophilic plaques, can be seen within the central fibres. $(\times 800$. $)$

VOL. $48 \mathrm{~B}$, NO. 1, FEBRUARY 1966 
was irregular and erythrocytes and polymorphonuclear leucocytes were seen inside some of them (Fig. 22).

Four days after injury-Many fibres appeared normal. Others exhibited disintegration of the contractile elements and sarcoplasm within more or less intact sarcolemmal sheaths. These

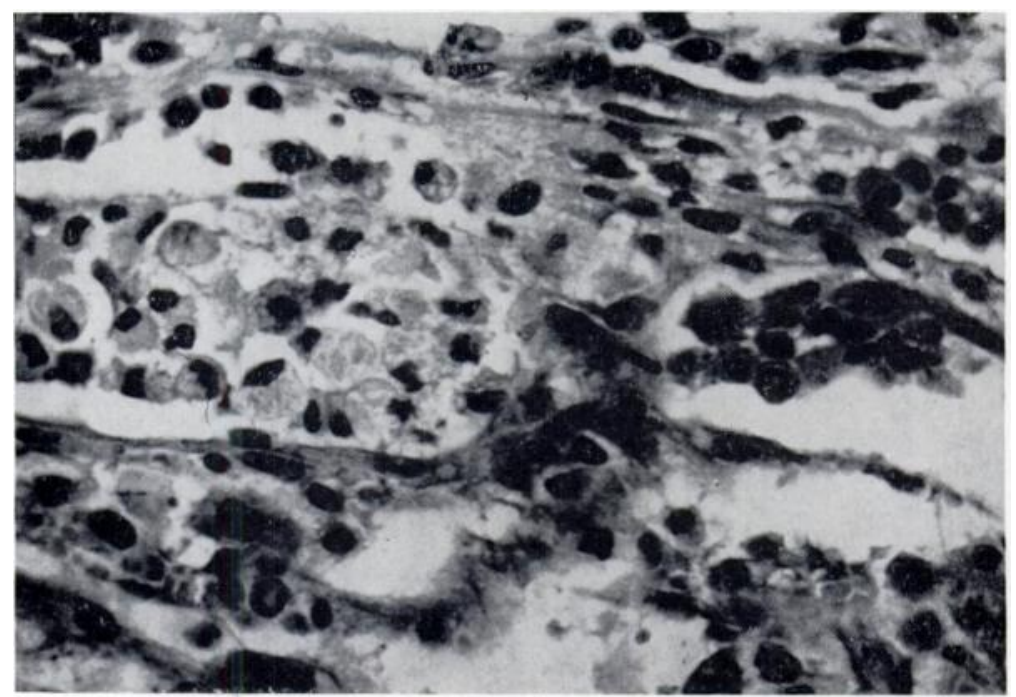

FIG. 24

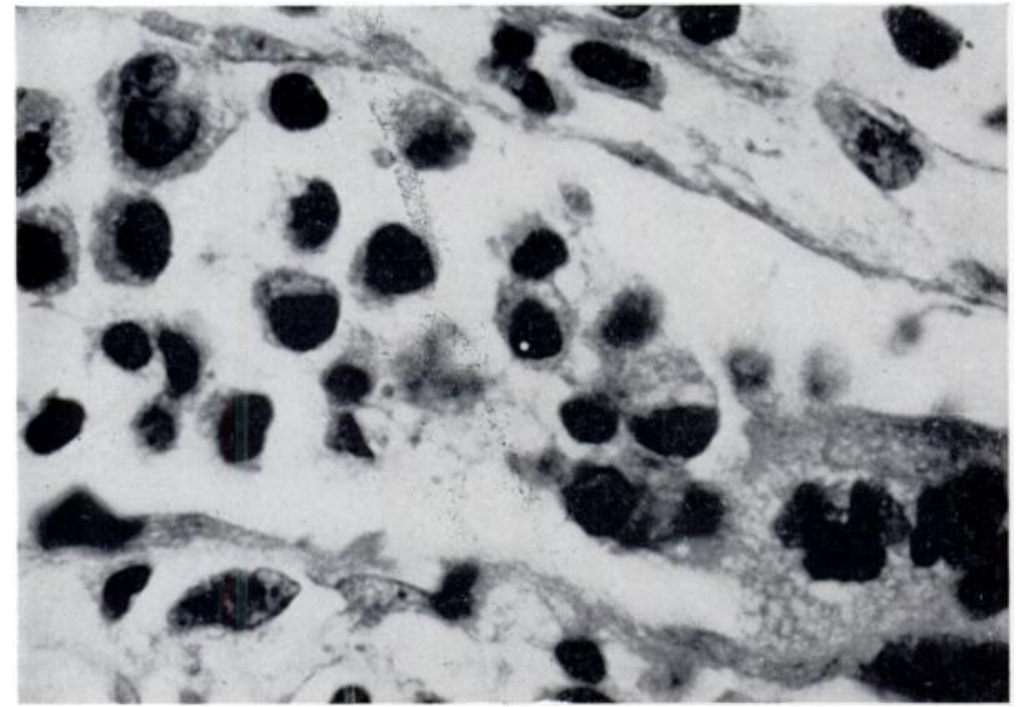

FIG. 25

Man. Ten days after trauma. Figure 24-The central fibre shows marked disintegration of its contents: typical phagocytic cells are seen on the left: a cluster of cells with large dark nuclei and little cytoplasm is seen at the right. $(\times 800$.) Figure 25-The central fibre shows a number of cells with dark nuclei and little cytoplasm within an intact sarcolemmal sheath: numerous cytoplasmic processes can be seen which pass from cell to cell. $(\times 2,000$.

fibres had no myofibrillar structure. Some of the subsarcolemmal nuclei appeared normal. Numerous phagocytic cells were seen scattered amidst the disintegrated fibre contents. Many of these cells contained granular eosinophilic debris. Phagocytosis was seen only in those fibres which had lost their myofibrillar or filamentous structure (Fig. 23).

Ten days after injury-Many of the muscle fibres appeared normal. As many others showed advanced phagocytosis of disintegrated muscle protein within apparently normal sarcolemmal 
sheaths. Clones of phagocytic cells were seen, each containing plaques of eosinophilic material in its vacuolated cytoplasm. In some parts of the traumatised area there were groups of myoblasts of a different appearance; the nuclei were large and densely staining; the amount of cytoplasm was small but was basophilic. The cells were in groups joined by numerous fine cytoplasmic processes passing from cell to cell (Figs. 24 and 25).

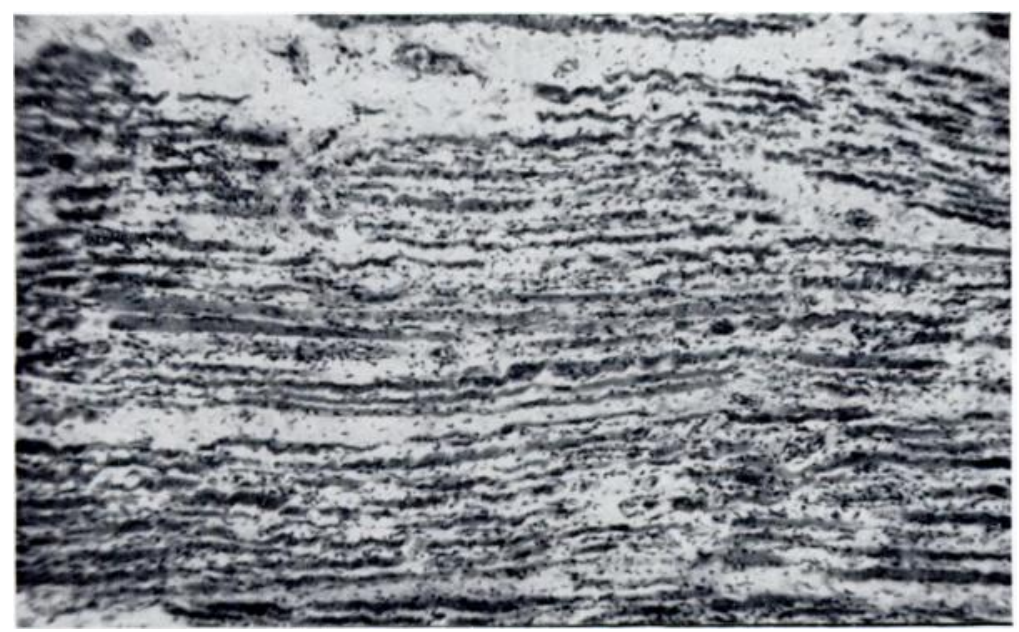

FiG. 26

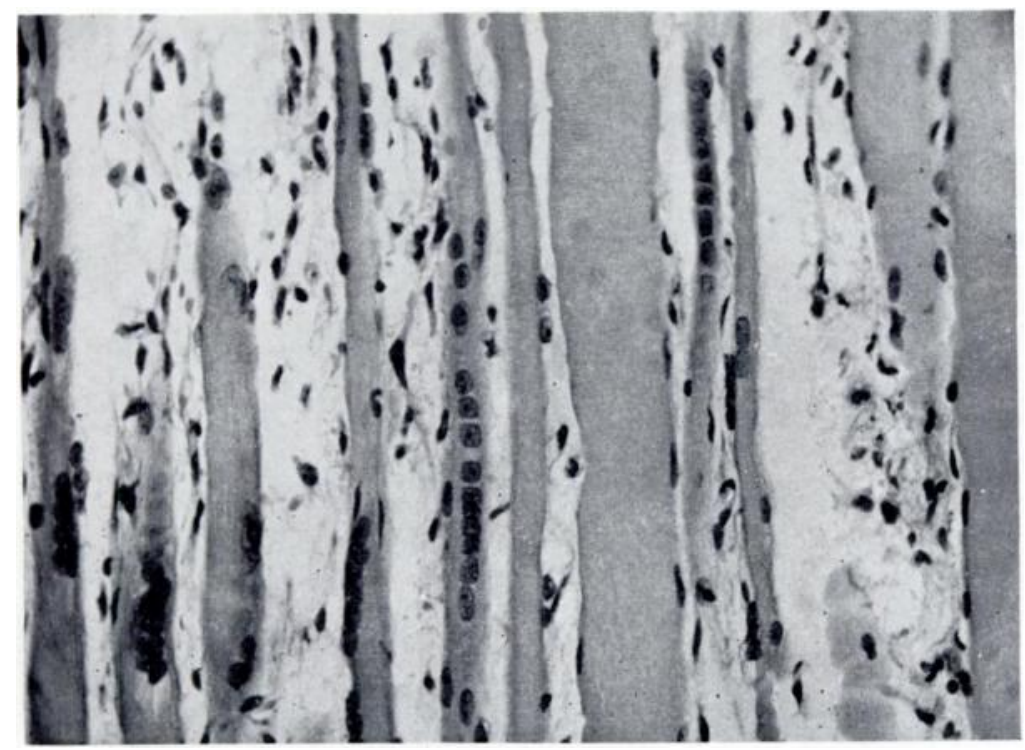

FIG. 27

Man. Thirteen days after injury. Figure 26-The whole field is occupied by thin, wavy fibres with chains of centrally placed nuclei. $(\times 70$. $)$ Figure $27-$ Two wide normal fibres with peripheral nuclei can be seen: the remainder of the field is occupied by thin newly formed fibres: these contain chains of large round myoblast nuclei which are placed in the centre of the fibre. $(\times 330$.)

Thirteen days after injury-Interspersed between normal fibres were large areas containing many small diameter basophilic muscle fibres, with centrally placed chains of myoblast nuclei typical of embryonic or regenerating muscle. In such a fibre the nuclei contained one or two prominent nucleoli and on either side of the central nuclear chain were myofibrils in which, under high magnification, a typical sarcomeral pattern of cross striations could be identifie $d$ 
(Fig. 28). This material shows clearly that a degree of muscle regeneration can and does occur, following phagocytosis of severely damaged muscle protein. Between these fibres are new interstitial collagen and fibroblasts (Figs. 26 to 28).

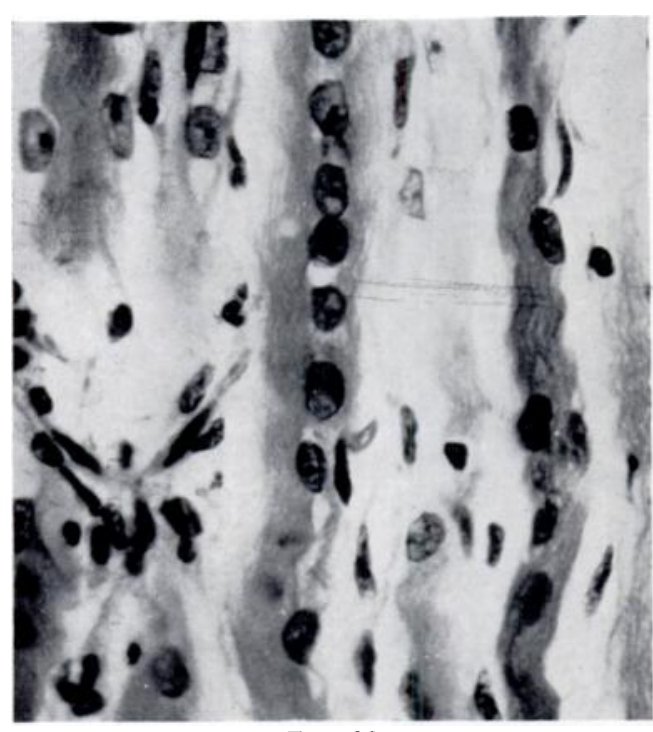

FIG. 28

Man. Thirteen days after injury. The central fibre shows clearly a chain of closely packed myoblast nuclei, each with one or two prominent nucleoli: peripheral to the nuclei are newly formed filaments of contractile protein: cross striations can be seen in some parts of the fibre. $(\therefore 800$.)

Eighteen days after injury - Scattered between normal areas were others in which the process of regeneration could be interpreted as nearing completion. In these areas the newly formed fibres were of greater diameter and less basophilic than at thirteen days after injury. The nuclei were more numerous than in normal muscle fibres; some of them were seen at the periphery of the fibres; others were placed centrally in the fibres; in some fibres the nuclei were seen as a central chain but the chains of closely packed nuclei seen at thirteen days were absent. Normal cross striations could be seen in many fibres. The overall appearance (Figs. 29 and 30) was midway between that of normal muscle (Fig. 16) and that of actively regenerating muscle.

One, three and six months after injury-Sections showed only an excessive amount of collagen adjacent to the fracture callus. Apart from this, the appearance of the muscle was entirely normal. This may have been severely injured muscle in which the process of regeneration was complete; or it may have sustained a minor degree of injury and recovered quickly: or it may never have been injured at all, though this is unlikely. The main value of the experimental work on monkeys is in attempting to elucidate this point.

\section{DISCUSSION}

This paper describes the main cytological changes in muscle that follow direct injury to soft tissue associated with a bone fracture.

The experiments on vervet monkeys demonstrate the time sequence of these changes. Because the tibia was intact the animals moved normally within a few hours of injury. Histological examination of biopsies indicated that when a standard force was applied to a known area severe scattered muscle fibre lesions were produced. During the first three to four days after injury affected muscle protein was phagocytosed. From six to twelve days myoblastic activity was obvious, and myotubes were formed. By twenty-one days regeneration of muscle cells was complete, apart from growth in diameter of the fibres, thou, xcess collagen persisted between bundles of muscle fibres, especially near the fracture callus.

Examination of muscle biopsies from human fracture cases is easy to describe but difficult to interpret because of the variety of possible contributing factors. For example, it is rarely possible to know the energy or the extent of the traumatising force and it is therefore often difficult to be sure of the correct site in the muscle to biopsy. It seems reasonable to assume that, as in the experimental lesions in the monkey, so in human patients it is those areas which have the most severe muscle fibre necrosis and haematoma formation which undergo the cycle of tissue change leading to muscle regeneration.

A patient was referred to one of us (W. H. K.-W.) who had sustained a simple fracture of the lowest third of the humerus seven weeks previously. The fracture was united but there 


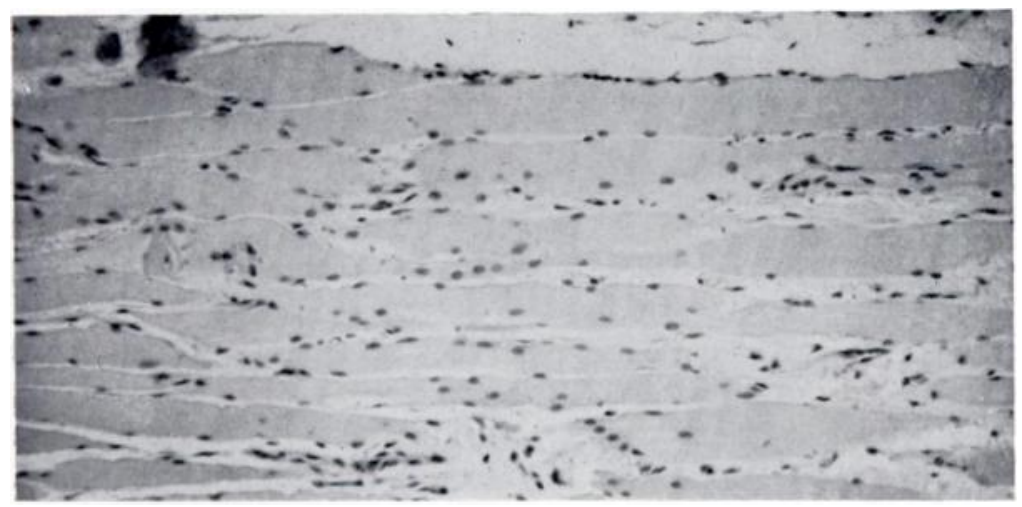

FIG. 29

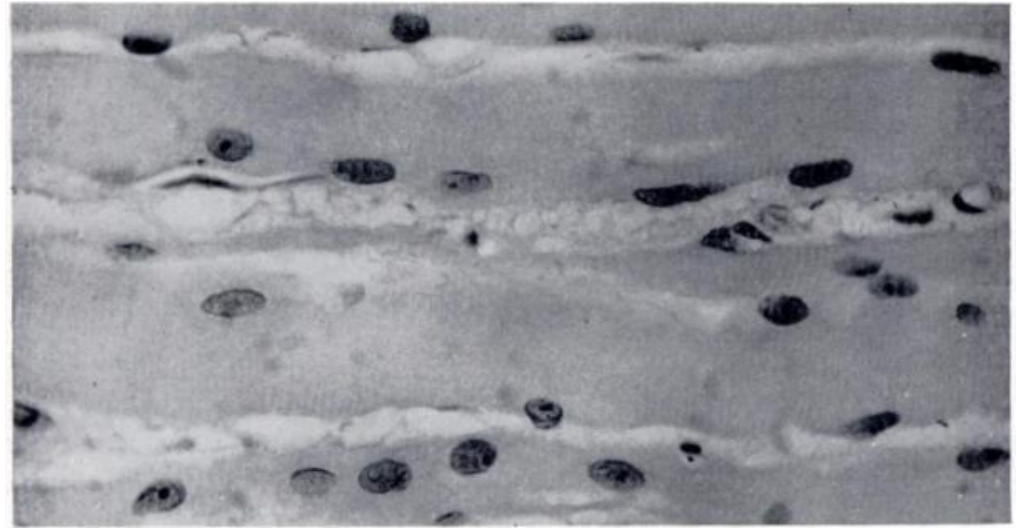

FIG. 30

Man. Eighteen days after injury. Figure 29-The whole field is occupied by newly formed fibres: the diameter of these is greater than at thirteen days, but not as great as that of normal fibres: the nuclei are numerous; some are peripheral and others central. $(\times 400$.) Figure 30-Segments of four fibres are seen: normal cross striation is present: the nuclei are large and active. The process of regeneration is nearly complete. $(\times 800$.)

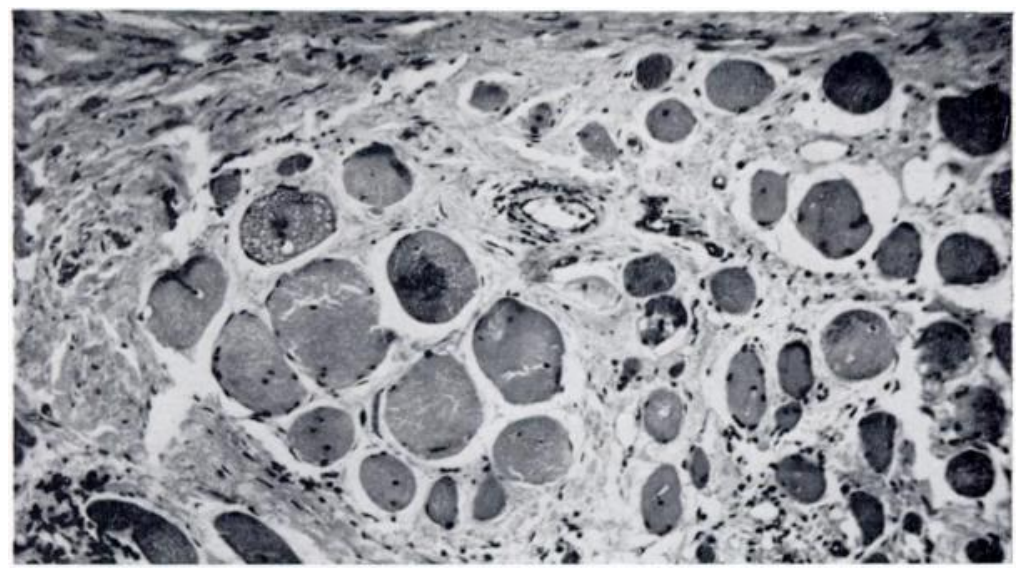

Fig. 31

Man. Seven weeks after injury: a cross-section of brachialis: following the injury the arm was immobilised in plaster from axilla to knuckles: no attempt was made to encourage active contractions of muscle: the nuscle fibres are few in number: many are of small diameter: in some of them (dark in colour) there has been an attempt at regeneration: surrounding these fibres is a large quantity of collagen which appears to be strangling them. $(\times 400$.) 
was a radial nerve palsy. The upper limb had been completely immobilised in plaster and no attempt had been made to encourage the patient to contract the muscles of the arm and forearm. At operation the radial nerve was found to be severed completely and surrounded by a mass of fibrous tissue. Three small muscle biopsy specimens taken from the brachialis (Fig. 31) showed individual narrow muscle fibres each surrounded by dense collagenous tissue, suggesting that regeneration had occurred but that this was functionally useless. It is concluded that rigid immobilisation and lack of use rather than denervation of brachialis were responsible for this condition.

Does early activity of the affected limb aid the dispersal of interstitial oedema fluid and limit intramuscular collagen formation? It seems likely that persistent tissue space oedema and excessive collagen deposition are closely or even causally associated. The effect of such intramuscular scar production would clearly be to isolate regenerating intramuscular fibres of both motor nerve and muscle, perhaps thereby preventing the formation of effective myoneural junctions. The dense periosteal fibrosis near the fracture callus clearly limits muscle regeneration in this area. But at a distance from the callus even severely damaged muscle appears to regenerate almost completely, providing there is no excess tissue space collagen to hinder the process.

In the animal experiments the monkeys began to move at once and within two days were running and jumping normally. In their case the tissue repair is therefore taking place where there is little chance for tissue fluid to accumulate by stasis.

The patients in this series were treated in a U-shaped plaster slab (humerus) or on Perkins' traction (femur, tibia and fibula). In all cases active contraction of the muscles of the injured limb was insisted upon from the beginning of treatment and through the succeeding weeks. Within a few days the patients were able to move the joints above and below the site of the fracture. By seven to ten days they were able to flex the knee 70 degrees or to abduct the shoulder and flex and extend the wrist fully. Thus almost full and painless joint movements were possible by the time of clinical union of the fracture. Oedema rapidly subsided and no case of long-standing post-traumatic oedema was encountered. Muscle power returned quickly. Union of the fractures was at least as rapid as would have been expected in such patients treated by complete immobilisation.

It is concluded that active joint and muscle movements provide a suitable " tissue environment" for both the soft-tissue regeneration and for union of the fractured bone of the injured limb.

\section{CONCLUSIONS}

1. Direct injury to skeletal muscle results in fragmentation and necrosis of muscle fibres, though this is patchy in distribution.

2. The sarcolemmal basement membranes form the interface along which fibre regeneration takes place.

3. Phagocytosis of disorganised sarcoplasm is an essential prelude to the reconstitution of severely damaged fibres.

4. Regeneration of injured muscle begins with proliferation of basophilic cells probably originating from muscle satellite cells. After a few days typical myoblast nuclear chains are present. By a week following injury the chains of myoblasts have formed myotubes, which possess myofibrils and sarcomeres.

5. By twelve days in the monkey and by eighteen days in man the muscle fibre regenerative process shows many new fibres which have not reached a mature diameter.

6. Much collagen may be formed in the tissue space at the site of injury. It appears that as the muscle fibres increase in diameter the collagen decreases in extent.

7. In the monkey by three weeks the muscle at the fracture site appears normal. This is also true in the specimens examined at four, six and twelve weeks. 
8. In the monkeys the injured limb was immediately used to run and jump. A parallel intense and early activity of muscle and joints was a cardinal point in the management of this series of fracture patients. The clinical results were satisfactory.

9. It is concluded that in both the monkey and in man, given active limb movements, permanent and functionally useful muscle regeneration occurs following soft-tissue injury associated with a bone fracture.

\section{REFERENCES}

Allbrook, D. B. (1952): The Reconstruction of Voluntary Muscle Following Injury. London University, Ph.D. thesis.

Allbrook, D. B. (1962): An Electron Microscopic Study of Regenerating Skeletal Muscle. Journal of Anatomy, 96, 137.

Allbrook, D. B., and Aitken, J. T. (1951): Reinnervation of Striated Muscle after Acute Ischaemia. Journal of Anatomy, 85, 376.

Bintuiff, S., and Walker, B. E. (1960): Radioautographic Study of Skeletal Muscle Regeneration. American Journal of Anatomy, 106, 233.

CAPERS, C. R. (1960): Multinucleation of Skeletal Muscle in Vitro. Journal of Biophysical and Biochemical Cytology, 7, 559.

Clark, W. E. Le Gros (1946): An Experimental Study of the Regeneration of Mammalian Striped Muscle. Journal of Anatomy, 80, 24.

Harman, J. W., and Gwinn, R. P. (1949): The Recovery of Skeletal Muscle Fibers from Acute Ischemia as Determined by Histologic and Chemical Methods. American Journal of Pathology, 25, 741.

Holtzer, H., Marshall, J. M., Jun., and Finck, H. (1957): An Analysis of Myogenesis by the Use of Fluorescent Antimyosin. Journal of Biophysical and Biochemical Cytology, 3, 705.

Konigsberg, I. R. (1961): Some Aspects of Myogenesis in Vitro. Circulation, 24, 447.

Mauro, A. (1961): Satellite Cell of Skeletal Muscle Fibers. Journal of Biophysical and Biochemical Cytology. 9, 493.

Moore, D. H., Ruska, H., and Copenhaver, W. M. (1956): Electron Microscopic and Histochemical Observations of Muscle Degeneration after Tourniquet. Journal of Biophysical and Biochemical Cytology, 2, 755.

Movat, H. Z. (1955): Demonstration of all Connective Tissue Elements in a Single Section. Archives of Pathology, 60, 289.

Muir, A. R., Kanji, A. H. M., and Allbrook, D. (1965): The Structure of the Satellite Cells in Skeletal Muscle. Journal of Anatomy, London, 99, 435.

Perkins, G. (1958): Fractures and Dislocations. University of London: Athlone Press.

Pogogeff, I. A., and Murray, M. R. (1946): The Form and Behavior of Adult Mammalian Skeletal Muscle in Vitro. Anatomical Record, 95, 321.

Saunders, J. H., and Sissons, H. A. (1953): The Effect of Denervation on the Regeneration of Skeletal Muscle after Injury. Journal of Bone and Joint Surgery, 35-B, 113.

Walker, B. E. (1963): The Origin of Myoblasts and the Problem of Dedifferentiation. Experimental Cell Research, 30, 80. 